\title{
CLOUD-BASED PROJECT MANAGEMENT: SELECTING IT SOLUTIONS FOR CONSTRUCTION COMPANIES
}

\author{
Gage Christianson ${ }^{1}$, Evan Wilson ${ }^{2}$, Matthew Henke ${ }^{3}$, Omar Alhnaity ${ }^{4}$, and Dr. Jeong-Han \\ $\mathrm{Woo}^{5}$
}

\begin{abstract}
Cloud Based Software (CBS) has transformed the construction industry. CBS allows its users to access information from anyplace, at any time, given they have a platform, device and internet to access it. CBS programs have also developed from specialized programs in one company function, to specialized programs in several areas in the construction field, such as: daily logs, document/photo storage, prequalification, and scheduling. CBS has proven to significantly increase productivity and communication in the construction company. A research survey was conducted for construction companies in the Mid-West about their current usage of CBS programs. It was found that $84.4 \%$ of respondents reported having to use three or more different construction programs due to the fact that none completely satisfied all their cloud integration needs. $81.8 \%$ of respondents also reported inefficiently operating at less than two company functions per program. Respondents stated frustrations that programs are not all-inclusive and do not contain all of the day-today functions needed to run their project on one platform. This is evidence of the need for one program to be used for all daily company functions. It was found through research and analysis that there are all-in-one CBS programs available in the current market.
\end{abstract}

Keywords: Construction Information Technology (CIT), Cloud-Based Software (CBS), Construction Software Analysis, Construction Project Management, Construction Data Survey.

\section{INTRODUCTION}

A new technological surge has begun amongst industry leaders in the construction and project management industry that involves the use of construction information management on cloud-based software's (CBS). CBS programs can drastically improve collaboration between project managers, supervisors, QA/QC managers, office managers, and field managers/foreman. There are many different types of cloud based software programs currently available on the internet. Some for free, others at a cost. Only some of these are construction project and company management based software programs. Others are more focused on financial/cost control or online document storage and collaborations.

The majority of these programs are typically geared towards, or used for, certain singular functions involved with a construction company: i.e. daily logs, photos/construction documents, or time clock management. Some companies use cloud based software for photos, some use it only for scheduling needs, and many respondents

\footnotetext{
${ }^{1}$ MS Civil Engineering/CM Specialty Class of 2018. MSOE.christiansong@msoe.edu

${ }^{2}$ MS Civil Engineering/CM Specialty Class of 2017. MSOE. wilsone@msoe.edu

${ }^{3}$ MS Construction/Business Management, Class of 2017. MSOE. henkemt@msoe.edu

${ }^{4}$ MS Construction/Business Management, 17’, BS Civil Engineering. MSOE. alhnaityoi@msoe.edu

${ }^{5}$ Associate Professor Civil and Architectural Engineering. MSOE. woo@msoe.edu
} 
claimed to not be using CBS at all. Ultimately, most companies pick and choose what they want to use IT strategies for rather than invest their entire company into it.

The idea of this research paper is that if you can find a single program that can bridge across all company functions, you can bring the company together as a whole into one program that is easily accessible from any place in the world. Theoretically, this would loosen the bounds on what one calls the office because the office is always at your fingertips; if you have the internet and a phone or computer to access it that is.

The strategies of this paper are to survey variously sized construction companies in the Mid-West region of the United States of America to gauge their current usage of CBS programs. Once this was analysed, data and respondent comments are presented that suggests the need for a CBS program that spreads across multiple company functions. The second part of the paper is to find an all-inclusive construction project management cloud system that can be used, industry and sector wide, for businesses small and large, that includes multiple functions for use in day-to-day construction activities, on one single platform.

\section{RESEARCH METHODS}

\subsection{Problem Statement}

There is a lack of cloud-based project management platforms geared toward construction companies that bridge across multiple construction functions (daily logs, photos, videos, lead tracking, proposals, warranties, scheduling, etc.). The idea of an all-inclusive program is that it allows for proper management and collaboration on projects between company executives, project owners, project managers/supervisors, subcontractors, architects, and misc. organizational staff. It allows the tracking and data storage of many different projects and project functions, from the beginning stages of presale, all the way to closeout.

\subsection{Goals}

- Assess/analyse need for non-extant, all-inclusive cloud-based construction project management (CPM) IT solutions.

- Analyse current construction industry trends pertaining to cloud programs.

- Help define and select an all-inclusive cloud based project management solution.

\subsection{Methodology}

The programs are chosen through Google search, Capterra (business software ratings), surveys and personal interviews to be further analysed to find the best all-around cloud program that favours companies in the construction industry. The goal of this research is to assess/analyse the need for non-extant, all-inclusive cloud-based construction project management IT solutions, current construction industry trends pertaining to cloud programs, and help define and select an all-inclusive cloud based project management solution for construction companies and contractors. A literature review was conducted to gather other researchers' findings on current CBS usage and the challenges with regard to implementation of construction project management IT solutions. Additionally, a survey was distributed to contractors and project managers of construction companies that operate in the U.S. to gather information of current industry CBS usage. Lastly, a research and analysis was conducted for top-rated, all-inclusive CBS programs currently being used in the construction industry. 


\subsection{Research Outcomes}

- Cloud-Based Software can drastically improve organization and productivity for construction companies and their projects.

- Construction companies are using on average one software per function.

- Cloud-Based Software's that connect/'bridge' multiple functions (doc-sharing, photos, scheduling etc.) are the future trend in project management software.

- There is an all-inclusive software that connects/bridges multiple functions.

\section{LITERATURE REVIEW}

An in depth literature review was conducted to gather findings on challenges and successes with CBS in order to show there is a need for an all-inclusive program that bridges multiple construction functions into one. JBKnowledge has been conducting a research study since 2012 to understand construction technology trends. One of the most glaring statistics from this survey were that companies used upwards of three or more programs for their day to day company functions. This was primarily due to the fact that most programs did not have integration capabilities with other programs or did not have multiple tools to aid in the construction process (JBKnowledge, 2015). This coincided with our research which found that $67.5 \%$ of respondents used and paid for more than three different programs for all of their company's needs.

Multiple case studies and academia show that Information and Communication Technology (ICT), or CBS, enhances the productivity and success rate of construction projects (Ahmad et al., 2015) (Aqlan, 2014) (Murray, 2001) (Forbes \& Ahmed, 2011) ("Software in construction sector", 2010). If CBS programs have proven to result in enhanced productivity, why would an organization stop halfway and not integrate their entire company into an online platform?

The reasoning, from many of our survey respondents, are issues associated with time, training, or the ability to see the benefits that come from using such a program. Our survey respondents were asked to indicate limiting factors to implementation and regular use of cloud-based platforms. Of these, $48 \%$ reported that a chief concern was training on the respective platform; $45 \%$ considered functionality a limitation; $25 \%$ also labelled cost as a significant factor. The real problem is that many do not know of a program that is all inclusive, which means to have many different functions across many company departments and people relationships. Many survey respondents expressed frustration in the end comments that there isn't a program that could do everything. It can be safely presumed that within the construction industry, cost is not the single greatest limitation with regard to implementation and use of cloud-based software--that training and functionality or usage, and all-inclusiveness are far greater.

The true barrier to training and functionality is that many do not know of a program that is all inclusive, which means to have many different functions across many company departments and people relationships. Having a program that is multi-functional allows an employee to become more acquainted with that program through increased usage. It also allows a company to create a process manual that links all of the different functions together in order to more easily train employees. As such, employees can become better at working within a single program instead of mastering many. They also understand how their data entry affects other parts of the organization. This leads to better collaboration with different positions in the organization. (Christianson, 2017). 
A case study was conducted as to the other benefits that come from using cloud software for many functions. One small general contracting company in Anchorage, Alaska, used an "all-inclusive" CBS program to better run its day to day functions. It had previously used personal company servers in order to track information and files, which $49 \%$ of our survey participants also claimed to do. Issues with such a system were lost data, information being saved over or deleted, and inability to access in the field or cloud. Changing to a CBS software resulted in massive productivity increases in the field and office, better communication between company project managers, better communication and satisfaction with owners, and faster responses to warranties, RFI's, Addendums, and change orders. CBS provided unlimited data storage to track daily logs, schedules, time clocks, and other management functions for each of the company's individual projects, approximately 200 a year. It also gave company executives better supervision and control over the employees they over sought (Christianson, 2017).

Lastly, an old paper from 2001 analysed the difficulties of choosing a program due to the consistent advancements of programs. Even if it's concluded that cloud-based project management software solutions or individual programs are optimal for contractors in the here-and-now, the technology could be obsolete within a year, given the pace of advancements in both software and hardware (Liberatore, M. J., Pollack-Johnson, B., \& Smith, C. A., 2001). This was confirmed by a construction industry professional from our survey;

"One of the bigger challenges we have seen is that small to mid-sized software firms exist for a few years then are acquired by larger companies who may not support the software in the same fashion, or may simply purchase to eliminate competition from a rival platform that they already own. Construction firms need to be nimble to adapt their processes to the changing landscape and recognize that the platform they use today may be entirely different 3-5 years from now."

In essence, companies that choose to use CBS programs must have processes that remain adaptable in order to alter them to changes in their current software or the need to change to new software.

\section{DATA \& RESULTS}

\subsection{Survey Analysis}

The survey information, pertaining to current cloud program trends in the Mid-West construction industry, will be provided as it relates to communication, usage, and productivity. Also, a comparative analysis of the most all-inclusive cloud software programs will be conducted for a recommendation of usage by the construction industry. This study attempts to bridge the knowledge gap created by the rapid advance in technology relative to general industry awareness of said technological advances.

Specifically, technology advances in regard to 'catch-all' or "all-in-one" cloud-based CPM software solutions. The survey respondents first indicated their area of employment within the general construction industry. There was significant diversity among the 77 who responded in terms of sector, size, and amount of work: 46 in Commercial, 16 in MEP Systems, 13 in Industrial and 10 in Engineering. Among the respondents, of particular note, were 38 project managers and 14 engineering/design professionals, alone comprising $66 \%$ of the sample. The results indicated that the more subjective, experience/opinionbased results of the survey are reflective more of larger-size construction firms than small and medium-size firms. 9\% worked for companies having 1-20 employees, $16 \%$ with 20- 
100 employees, $22 \%$ with $100-500$ employees and $54 \%$ of with $500+$ employees. This is affirmed by the next key quantitative survey item: of those surveyed, $62 \%$ belonged to firms managing one to five projects per year, indicating larger firms managing fewer, larger jobs; $17 \%$ reported an average of six to ten projects per year; the remainder managed or worked on 11 projects or more per year on average.

77 respondents, from 32 different companies, indicated that they had used some kind of cloud-based software in the course of their job/at their business. Respondents were asked to indicate which cloud-based software their companies use. Among the various cloud-based platforms available, Bluebeam is the most commonly used software (79\% of respondents), followed by BIM 360 (55\%), Procore (43\%), Box (39\%), Multivista (11\%) and Sage (10\%). About half (49\%) indicated that their firms also facilitated their own cloudbased hosting via private company server. Table one shows all of the different ways that these CBS programs were used for functions in the respondents' companies.

Table 1: Uses of Cloud-Based Software, By Platform

\begin{tabular}{|c|c|c|c|c|c|c|c|c|c|c|}
\hline Answer Options & 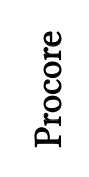 & $\sum_{m}^{\infty}$ & 番 & ڤ્a & 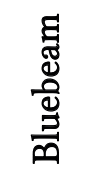 & 葋 & 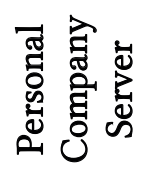 & $\frac{\vec{\Xi}}{\Xi}$ & 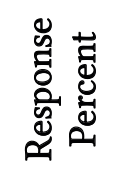 & 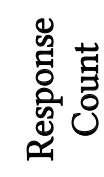 \\
\hline Field Data Collection & 21 & 27 & 4 & 17 & 35 & 7 & 23 & 7 & $50.6 \%$ & 39 \\
\hline Project Management & 29 & 36 & 6 & 25 & 47 & 8 & 32 & 10 & $75.3 \%$ & 58 \\
\hline Estimating/Take-offs & 11 & 25 & 5 & 15 & 32 & 4 & 25 & 4 & $45.5 \%$ & 35 \\
\hline Prequalification & 4 & 6 & 2 & 5 & 6 & 0 & 7 & 2 & $11.7 \%$ & 9 \\
\hline Accounting & 9 & 11 & 5 & 9 & 11 & 2 & 11 & 3 & $18.2 \%$ & 14 \\
\hline BIM & 22 & 33 & 6 & 21 & 36 & 7 & 26 & 9 & $54.5 \%$ & 42 \\
\hline $\begin{array}{l}\text { Invitation to Bid / } \\
\text { Plans Room }\end{array}$ & 10 & 18 & 3 & 14 & 22 & 4 & 16 & 8 & $35.1 \%$ & 27 \\
\hline Project Scheduling & 9 & 11 & 0 & 6 & 11 & 3 & 8 & 3 & $19.5 \%$ & 15 \\
\hline Time Clock & 4 & 7 & 0 & 4 & 8 & 0 & 8 & 3 & $11.7 \%$ & 9 \\
\hline All & 4 & 4 & 0 & 4 & 7 & 1 & 5 & 3 & $9.1 \%$ & 7 \\
\hline Other & 1 & 1 & 1 & 1 & 3 & 1 & 2 & 3 & $3.9 \%$ & 3 \\
\hline Total & 124 & 179 & 32 & 121 & 218 & 37 & 163 & 55 & & 258 \\
\hline
\end{tabular}

The analysis of the different ways that CBS programs were used for functions in their company led to a discovery that many companies were using many different types of programs for multiple functions. It was discovered that $59.7 \%$ of respondents used more than three programs while $67.5 \%$ of respondents used CBS for more than three company functions. This close relation led us to analyse how many of these companies were using one program per company function.

An analyses was done to calculate the number of programs used versus the number of business functions used for each survey respondent. The ratio of functions to programs was used as an indicator of a respondent's company's level of usage of CBS to perform their company's functions. A scale of 0.0-1.0 is a very poor score and indicates that a company is using more programs, or the same amount of programs, as they are integrating 
functions. A 1.01-1.99 indicates that a company is beginning the process of integrating more functions of their company into a single platform. A 2.0 or higher score indicates that a company is using at least one program for two of its company's functions. Companies greater than a 2.0 are using all-inclusive CBS programs that have proven to enhance productivity and communication because they can bridge across many construction company functions.

Table 2: Programs vs. Business Functions

\begin{tabular}{ccccccccc}
\hline & \multicolumn{7}{c}{ Number of Company Functions } \\
Programs & $\mathbf{1}$ & $\mathbf{2}$ & $\mathbf{3}$ & $\mathbf{4}$ & $\mathbf{5}$ & $\mathbf{6}$ & Total & \% of Use \\
\hline 1 & 8 & 4 & 2 & 1 & 0 & 2 & 17 & $22 \%$ \\
2 & 3 & 3 & 4 & 1 & 1 & 2 & 14 & $18 \%$ \\
3 & 1 & 4 & 4 & 6 & 1 & 1 & 17 & $22 \%$ \\
4 & 0 & 2 & 2 & 3 & 1 & 4 & 12 & $16 \%$ \\
5 & 0 & 0 & 3 & 1 & 2 & 4 & 10 & $13 \%$ \\
6 & 0 & 0 & 1 & 1 & 1 & 4 & 7 & $9 \%$ \\
Total & 12 & 13 & 16 & 13 & 6 & 17 & 77 & \\
\hline of Use & $15.6 \%$ & $17 \%$ & $21 \%$ & $17 \%$ & $8 \%$ & $22 \%$ & & \\
\hline
\end{tabular}

Only 22\% of respondents used one CBS program for their company's functions. Less than $50 \%$ scored above a 2.0 value. In fact, less than $18.2 \%$ of respondents scored above a 2.0. $88.8 \%$ of respondents finished with less than a 2.0 value with $55.8 \%$ finishing at a 1.0 or less. This means that of the 77 respondents, 43 are using one or more programs for each of their company functions. Only 14 of respondents are consistently using all-inclusive software's that integrate many of their company's functions into a CBS platform. All of which were using some variation of Bluebeam along with their own company server or CBS platform. This trend shows that companies are using specialty programs for each function rather than integrate them. This leads to information being lost, continuous double entry, and poor inner company communication between different 'divisions'; i.e. engineering to project management to accounting. (Christianson, 2017).

Table 3: Compiled Data for Programs vs. Business Function

\begin{tabular}{ccc}
\hline Score & Respondents & \% of Total Respondents \\
\hline $0.0-1.0$ & 43 & $55.8 \%$ \\
$1.01-1.99$ & 20 & $26.0 \%$ \\
$2.0+$ & 14 & $18.2 \%$ \\
\hline
\end{tabular}

\subsection{All-Inclusive Cloud Program Analysis}

A software analysis was conducted for the products BIM 360, Procore, BlueBeam, BuilderTREND, Box, Fieldwire, Co-Construct, \& Sage Software 300 Construction. The analysis sought to compare the amount of functions available through each program in 
order to find the program that had the most modules, which satisfied our definition of an all-inclusive program. Some of the most important functions from respondents of the survey that they wished they could use in CBS were: Field Data Collection (48.48\%), Project Scheduling (30.3\%), Estimating/Take-offs (27\%), or All functions (25.76\%). This confirms our suspicion that there is at least some need for an all-inclusive software.

The results of this program analysis found that the most all-inclusive cloud programs pertaining strictly to the construction industry were, BlueBeam, ProCore and Buildertrend Procore allows construction industry professionals to seamlessly synchronize project management and accounting in one single platform. This software does not change your everyday tasks at all, instead, it provides integrations with the best accounting, scheduling, file sharing, and estimating applications in the industry today. While Procore is focused primarily on document and project collaboration between the organization, owner, and architect, in other words, project management, Buildertrend is more focused on company management as well as project management. Buildertrend executive interface allows for a project manager or company executive to overview everything going on within the company and each individual job. Unlike Procore, Buildertrend extends beyond the project construction into pre-qualification and post-construction relations. This includes lead tracking and communication, activity tracking, proposal and estimate generation, homeowner login integration, product selections, surveys, warranty tracking, and even a time clock program (Santos 2014). A large percentage of construction firms use Bluebeam in conjunction with their other programs. Bluebeam is an excellent program for document collaboration and estimating take-offs. It does not however, have the many features that also accompany Procore or Buildertrend and as such it is not deemed an all-inclusive program suitable for the constraints of this research.

One of the biggest benefits that both companies bring to the table is the mobile app. Our survey as well as the survey conducted by JBKnowledge found that that $97 \%$ of companies use their mobile smartphone on the jobsite to view and track information. Furthermore, it was found that $80 \%$ of those companies found it important or very important that the programs have a mobile applications or mobile usability (JBKnowledge, 2015). Smartphone usage has allowed for enhanced productivity and is the entire basis for the reasoning behind cloud software. The ability to see and enter information away from the home office saves countless hours of unproductivity and lack of communication. It is clear that the growing trend in the industry is the need for CBS programs that can be used by phones or tablets.

\section{CONCLUSION}

The research shows that the construction industry is in need for an all-inclusive cloud based construction management program to bridge many functions that occur within a construction company. Through in depth literary analysis and a survey distributed to construction industry professionals, research has concluded that $84.4 \%$ of respondents reported having to use more than three different construction programs due to the fact that none completely satisfied all of their cloud integration needs. $81.8 \%$ of respondents scored less than a satisfactory $2.0 \mathrm{C}-\mathrm{W}$ factor. The data analysis is meant to be a gauge of how well a company has begun integrating many functions into CBS programs. This high percentage of low scores indicates that companies have not begun to integrate more than two of their company's functions into a single online platform, and are instead using one program for each of their company's functions. This has proven to lead to loss of information, double entry from transferring files, poor inter-company communication, 
and delays and lags in communication between other stakeholders in the project such as owners and subcontractors.

Additionally, the data and research has shown that the vast majority of companies use IPhone or androids on the jobsite to view and track information. The introduction of smartphones into the construction environment has led to enhanced productivity and is the entire basis for the reasoning behind cloud software. The ability to see and enter information away from the home office saves countless hours of unproductivity and lack of communication. It is clear that the growing trend in the industry is moving towards cloud software which allows for instantaneous communication and more productivity. Phones and tablets will play a very large role in that communication and usage in the field. As such, CBS programs and their developers should make them phone and tablet compatible. A survey respondent said "First-hand experience has shown that this saves the field thousands of hours by not having to do the quantity take offs and submit written daily logs to be double entries. This leaves us more time to manage [other project needs]."

Procore and Buildertrend are the cloud management programs that are the easiest to use, train employees, and bridge across multiple functions. Procore was found to be better used for construction management or contracting companies that spend the majority of their time doing document and subcontractor/architect collaboration. Buildertrend was found to work better for a general contracting companies. Both have management tools that extended beyond the project duration and completion and into pre-construction, lead tracking/qualification, as well as project owner integration, accounting, and satisfaction relations such as surveys and warranty on projects. While both of these programs were found to be all inclusive, other programs such as Bluebeam, Box, Quickbooks/Sage, and scheduling programs such as Oracle or MS project. were still found to be relevant as they could focus on one activity in general, and be most efficient at it. The solution for this by any all-inclusive program, such as Buildertrend or Procore, is not always to replace one of those programs but to make their programming compatible to work in integration with their platform to reduce double entry and keep communication in one place.

\section{REFERENCES}

Ahmad K., Parvez S., Cehtan D. and Sushant G. (2015). Cloud Services for Collaborative Web Based Project Management System.

Aqlan, S. A. (Jan, 2014). Impact of engineering software on construction project management in Bahrain. Applied Mechanics and Materials, 501-504

Christianson, G. (2017). Implementing lean into cloud-based project management programs for a small construction company. Unpublished manuscript, Milwaukee School of Engineering.

JBKnowledge (2015). Construction Technology Report, Report.

Forbes, L. H. (2011) Modern Construction: Lean project delivery and integrated practices. CRC Press, 203-230.

Liberatore, M. J., Pollack-Johnson, B., Smith, C. A. (2001). Project management in construction: Software use and research directions. Journal of Construction Engineering and Management, 127(2), 101-107.

Murray, M. (Oct., 2001). ICT tools are helping to make the construction process more productive. Civil Engineering: Magazine of the South African Institution of Civil Engineering, 9(9).

Santos, Jose Maria Delos (2014). Procore Software Review: Overview - Features - Pricing. https:/project-management.com/procore-software-review/ 
Christianson G., Wilson E., Henke M., Alhnaity O., and Dr. Woo J.

NBM\&CW (2010). Computer Software in Construction Sector, New Building Materials and Construction World. New Delhi.

\section{APPENDIX}

Survey Results: http://www.surveymonkey.com/results/SM-T5LLVX6X/ 